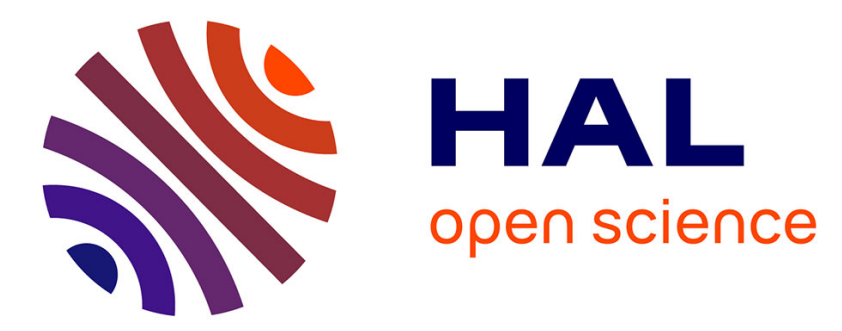

\title{
Experimental investigation of quasi-static and intermediate strain rate behaviour of polypropylene glass fibre (PPGF) woven composite
}

Antoine Martin, Ramzi Othman, Patrick Rozycki

\section{- To cite this version:}

Antoine Martin, Ramzi Othman, Patrick Rozycki. Experimental investigation of quasi-static and intermediate strain rate behaviour of polypropylene glass fibre (PPGF) woven composite. Plastics, Rubber and Composites, 2015, 44 (1), pp.1-10. 10.1179/1743289814Y.0000000110 . hal-01240019

\author{
HAL Id: hal-01240019 \\ https://hal.science/hal-01240019
}

Submitted on 12 Mar 2017

HAL is a multi-disciplinary open access archive for the deposit and dissemination of scientific research documents, whether they are published or not. The documents may come from teaching and research institutions in France or abroad, or from public or private research centers.
L'archive ouverte pluridisciplinaire HAL, est destinée au dépôt et à la diffusion de documents scientifiques de niveau recherche, publiés ou non, émanant des établissements d'enseignement et de recherche français ou étrangers, des laboratoires publics ou privés. 


\title{
Experimental investigation of quasi-static and intermediate strain rate behaviour of polypropylene glass fibre (PPGF) woven composite
}

\author{
A. Martin ${ }^{1}$, R. Othman ${ }^{2}$ and P. Rozycki ${ }^{1}$
}

This article covers an in plane experimental characterisation of a polypropylene glass fibre reinforced woven composite. Tensile, shear and compression loadings were carried out with a standard tensile rig and a crossbow/Hopkinson pressure bar rig. The specimen strain was measured by digital image correlation technique. It is concluded that the composite stiffness and strength are highly sensitive to strain rate. Static and dynamic multicycle tests were also undertaken to identify and quantify softening phenomenon. Thus, permanent plastic strain and reduction in stiffness are observed and quantified.

Keywords: Impact behaviour, Intermediate strain rate, Mechanical testing, Polymer-matrix composites

\section{Introduction}

Twintex ${ }^{\circledR}$, a commingled long glass fibre reinforced polypropylene woven composite, has high specific mechanical characteristics while being low cost. It can also be recycled; thus, it is an environmentally friendly material. Thus, polypropylene composites are good candidates to replace steel and metallic materials in transportation vehicles even for crash absorbing structures. ${ }^{1}$ Consequently, assessing the strain rate sensitivity of their mechanical behaviour is highly important to the development of valid numerical models. ${ }^{2}$

In the past decades, several works have dealt with woven reinforced thermoset polymer composites. ${ }^{3-13}$ Mostly, it was concluded that the compressive Young's modulus and strength increase with increasing strain rates, whereas a significant scatter was observed for the behaviour of the strain at failure.

Contrary to thermoset woven reinforced composites, thermoplastic woven reinforced composites have received less interest. Rodriguez et al. ${ }^{14}$ and Chocron Benloulo et al. ${ }^{15}$ evaluated the mechanical behaviour of aramid/polypropylene, aramid/polyethylene terephthalate and all polyethylene woven composites at three strain rates, namely $0 \cdot 001,1$ and $1000 \mathrm{~s}^{-1}$. They reported that the tensile strength and failure strain increases and decreases respectively, for increasing strain rates. The dynamic tensile strength can be $160 \%$ as higher as the quasi-static strength, and the strain at failure for dynamic experiments can be $60 \%$ as lower as

1LUNAM Université, GeM Institute, Ecole Centrale Nantes, 1 rue de la Noë, BP 92101, 44321 NANTES Cedex 3, France

${ }^{2}$ Mechanical Engineering Department, Faculty of Engineering, King Abdulaziz University, PO box 80248, Jeddah 21589, Saudi Arabia

*Corresponding author, email othmanramzi@gmail.com the quasi-static failure strain. Todo et al. ${ }^{16}$ measured the strain rate sensitivity of carbon/polyamid-6, carbon/ modified polyamid-6, glass/polyamid-6, glass/modified polyamid-6 woven cloth composites for strain rates ranging from $0 \cdot 01$ and $40 \mathrm{~s}^{-1}$. They observed that the tensile strength is increasing with increasing strain rates. The failure strain is also increasing with increasing strain rates excepting for glass/modified polyamide-6, where the strain at failure is almost constant. Consequently, the absorbed fracture energy is increasing in terms of strain rate for the four polyamide composites.

The glass fibre reinforced polypropylenes are increasingly used in automobile and aerospace engineering due to their low cost and high specific stiffness, strength and energy absorption. ${ }^{17-21}$ There is a confirmed tendency to use them in crash and impact resistant compenents. ${ }^{22}$ Consequently, it is particularly important to measure and model their mechanical properties over a wide range of strain rates. Hufenback et al. ${ }^{17}$ investigated the through thickness properties of Twintex using the $\mathrm{L}$ shaped specimen. Because of the stress and strain field heterogeneity, a linear elastic material behaviour until first failure was assumed. Furthermore, the elastic constants were assumed insensitive to strain rate. The methodology was original; however, the obtained results, as for inverse methods, are highly dependent on the assumed constitutive equation. ${ }^{23,24}$ Dealing also with Twintex, Govender et al. ${ }^{18}$ studied the impact delamination based on a modified three-point bending Hopkinson bar system.

Bonnet $^{19}$ studied the tensile and compression behaviour of $4: 1$ unbalanced Twintex under monotonic and multicycle loadings. Three orientations (warp, shear and weft) were investigated for strain rates ranging between $0 \cdot 1$ and $100 \mathrm{~s}^{-1}$. However, the same specimens were used for dynamic and quasi-static experiments. Hence, 


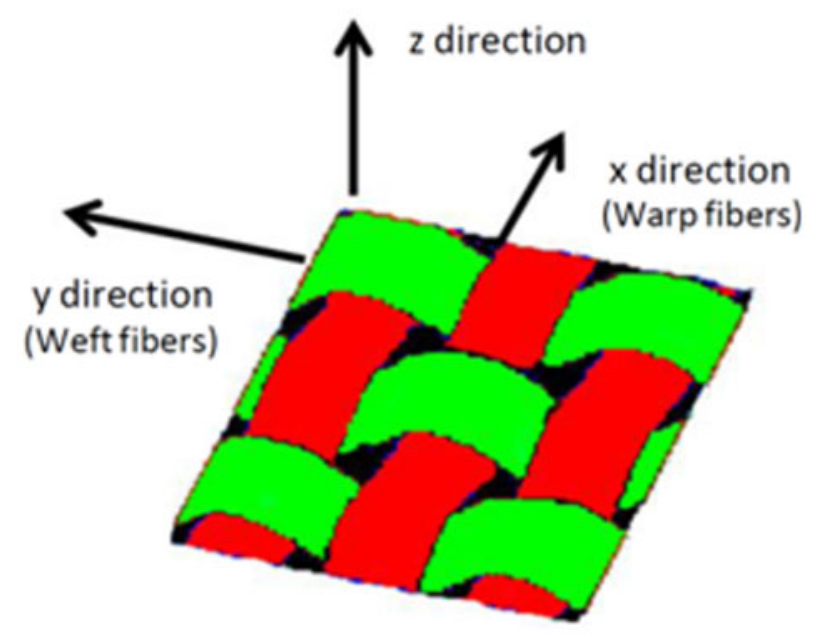

1 Twintex twill fabric schematic with coordinate system

strain and stress homogeneity could not have been achieved before $90 \mu \mathrm{s}$. Consequently, the measured average stress and strain are not representative of the stress and strain respectively fields in the specimen. Reyes and Sharma ${ }^{20}$ also investigated the strain rate sensitivity of the tensile behaviour of Twintex in quasistatic $\left(0 \cdot 00005-0 \cdot 05 \mathrm{~s}^{-1}\right)$ and dynamic $\left(200-500 \mathrm{~s}^{-1}\right)$ strain rate ranges. They dealt with two directions: 0 and $90^{\circ}$ (warp and weft). It was shown that the stiffness and strength increase, while strain at failure decreases for increasing strain rates. Brown et $a l^{21}$ dealt with a balanced Twintex with $60 \%$ fibre in weight. They evaluated the tensile, compression and shear behaviour for strain rates ranging from 0.01 to $100 \mathrm{~s}^{-1}$. It was observed that the compressive and tensile strengths and compressive and tensile moduli increase with increasing strain rates. However, the shear strength and modulus decrease with increasing strain rates. A piezoelectric load cell was used for dynamic experiments to record the force applied on the specimen. Nevertheless, force measurement could be accompanied by important oscillations at strain rates $\sim 50 \mathrm{~s}^{-1}$ and above. ${ }^{25} \mathrm{At}$ strain rates $\sim 50 \mathrm{~s}^{-1}$ and above, a Hopkinson bar method is rather preferred to piezoelectric load cells as suggested in Ref. 25.

From the above literature review, it can be concluded that very few works have dealt with the measurement of Twintex mechanical properties in the intermediate and high strain rate ranges. ${ }^{19-21}$ In this paper, we present a large experimental programme on Twintex. Both tensile and compression behaviour were investigated for strain rates ranging from 0.001 to $1000 \mathrm{~s}^{-1}$ and orientations ranging from 0 to $45^{\circ}$. Appropriate specimen dimensions were adopted for dynamic experiments, which are carried out on a crossbow system. ${ }^{26}$ We are also interested in both monotonous and multicycle or repeated loadings in order to investigated damage evolution. This is to investigate the sensitivity of damage evolution to the strain rate, which is highly understudied in the open literature. Jendli et al. $^{27}$ have proposed interrupted intermediate strain rate tensile experiments. Wang and $\operatorname{Sun}^{28}$ used a Hopkinson bar method. In this work, we propose a new methodology that consists in controlled impact energy crossbow system experiments. Hence, damage evolution, under intermediate strain rate compressive loads, can be measured.

\section{Method}

\section{Material and specimens}

The specific arrangement, used in this study, is depicted in Fig. 1 including the coordinate system. The material of interest is a commercial Twintex (E-glass/Polypropylene woven composite) with a balanced $60 \%$ fibre weight fraction and a $745 \mathrm{~g} \mathrm{~m}^{-2}$ ply weight. It was furnished in a commingled form by Owens Corning International and is now sold by Fibreglass Industries. The woven being balanced, no distinction is made between warp and weft directions, and testing was undertaken considering fibre angles between 0 and $\pm 45^{\circ}$ from $x$ direction. All experiments were carried out at room temperature $\left(\sim 21^{\circ} \mathrm{C}\right)$.

Staring from flat plates, specimens were machined using a standard numerical 3D milling machine. The rotating speed was carefully chosen in order to allow accurate cutting while avoiding melting. Tensile
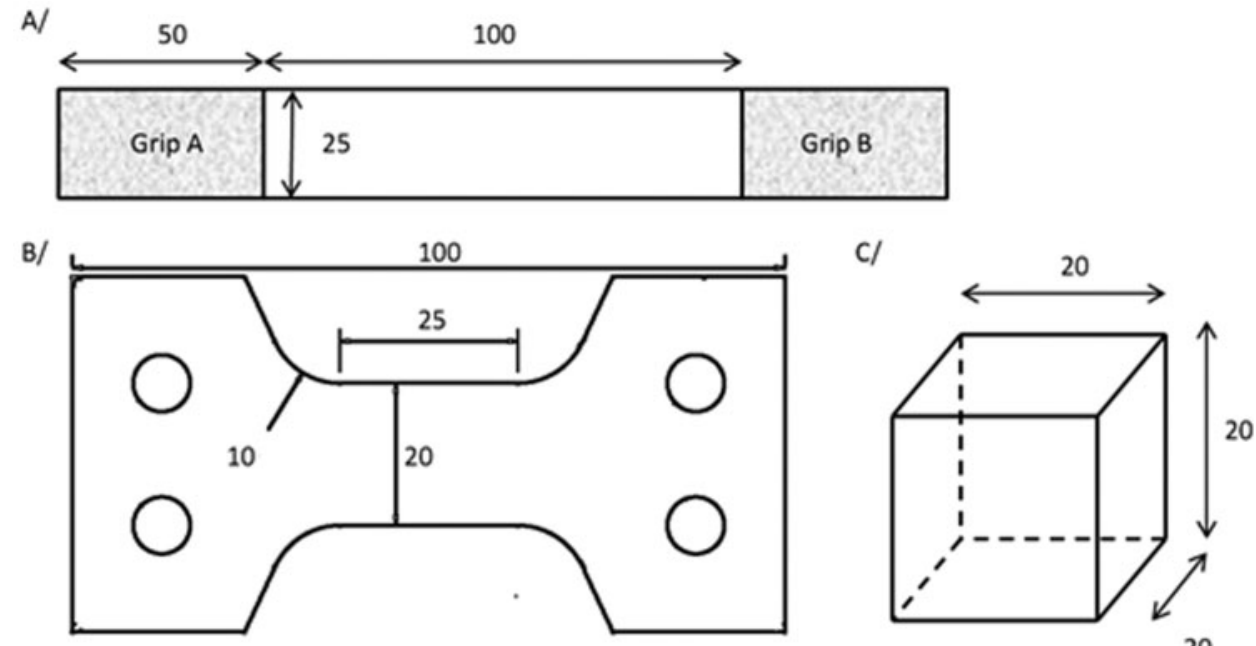

a quasi-static tensile experiments; $b$ dynamic tensile experiments; $c$ compression experiments (dimensions are given in millimetres)

2 Specimen geometries 


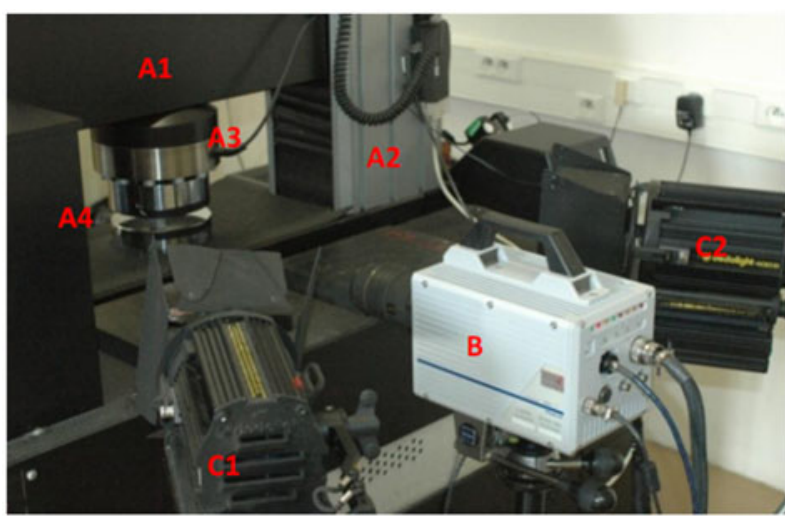

a INSTRON test rig; a1 transverse beam; a2 actuators; a3 load cell; a4 ANVILS for compression; $b$ camera; $c$ projectors

3 Intron $100 \mathrm{kN}$ test rig

specimens were cut from six-ply (3 $\mathrm{mm}$ thick) plates, while compression specimens were machined from 40ply $(20 \mathrm{~mm}$ thick) plates. In order to fabricate the composite plates, plies of unconsolidated cold material were firstly stacked. Subsequently, the material was sandwiched between two aluminium plates and heated inside an oven at $200^{\circ} \mathrm{C}$. Vacuum was set during heat phase. The plates were then cooled at room temperature. The material density is in line with supplier recommendation $\left(1490 \mathrm{~kg} \mathrm{~m}^{-3}\right)$. All specimens are machined large enough to contain one full repeating unit cell (RUC) of the material. The RUC is a square with $20 \mathrm{~mm}$ long sides. In order to match force levels with the specimen fixtures, it was not possible to include more than one RUC in specimen width. To improve average behaviour, a minimum of six-ply are then stacked.

Rectangular shaped flat specimens, measuring $200 \times 25 \times 3 \mathrm{~mm}^{3}$, were used for quasi-static tensile tests (Fig. 2a). Aluminium plates were bonded on the specimens' extremities, using cyanoacrylate adhesive, yielding a $100 \mathrm{~mm}$ long gauge part. Quasi-static tensile specimens are in line with ISO 527 recommendations. ${ }^{29}$ Two orientations were mainly considered: $\left[0^{\circ}\right]$ or $\left[ \pm 45^{\circ}\right]$ from $x$ axis. Two other orientations, namely $\left[+10^{\circ}\right]$ and $\left[+20^{\circ}\right]$, were also investigated for some experimental configurations. As there is no standard for dynamic tensile testing of composite materials, a custom designed dumbbell specimen, which is depicted in Fig. $2 b$, was used for dynamic strain rates.

Forty-ply thick cubes, with $20 \mathrm{~mm}$ long sides, were used for compression in both quasi-static and dynamic experiments (Fig. 2c). The specimen thickness is chosen in order to prevent buckling.

\section{Testing machines}

Quasi-static testing was carried out using a classical $100 \mathrm{kN}$ INSTRON electromechanical test rig (Fig. 3). Standard autofit grips were used for tensile, whereas two anvils were used for compression. A longitudinal sensor was used to measure axial strain. Dynamic testing was undertaken with a crossbow system (Figs. 4 and 5), ${ }^{26}$ which allows for testing materials under compression and tensile loads (Fig. 6). A projectile consisting in an axially guided mass ( $27 \mathrm{~kg}$ or $260 \mathrm{~kg}$ ) is propelled by elastic ropes. A wide range of rope configurations helps in targeting a desired kinetic energy. The compressive specimen was simply put in contact with a long elastic

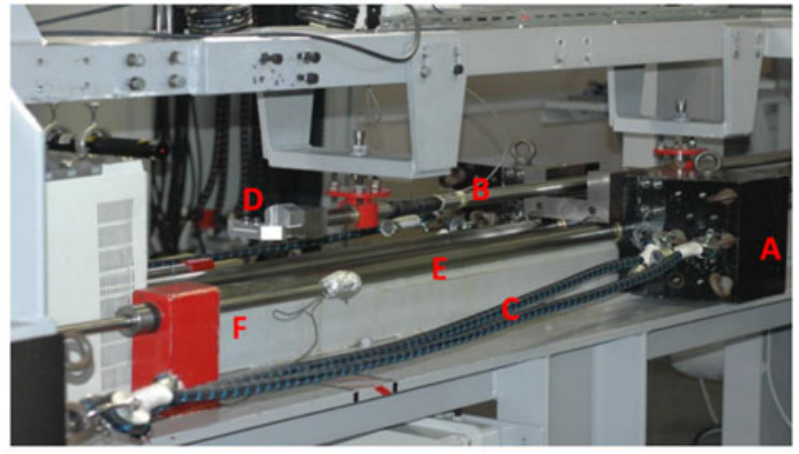

a impactor mass; $b$ receiver bar (tensile layout); $c$ elastics, $d$ specimens and specimen fixture; $e$ mass guide; $f$ excessive energy damper

\section{Crossbow system}

steel bar equipped with strain gauge station. Grease was in the specimen/bar to reduce friction effects. The tensile specimen was attached to the elastic bar through a specific grip. As the specimen is impacted by the projectile, a compressive/tensile elastic wave is transmitted to the bar and recorded by the strain gauge station. The bar is $6 \mathrm{~m}$ long and $30 \mathrm{~mm}$ in diameter. Actually, the bar length controls the test duration. Indeed, conventional Hopkinson bar-like processing is valid for one wave roundtrip in the bar. ${ }^{25}$ The longer the bar is, the longer the test duration will be. The $6 \mathrm{~m}$ long bar yields an approximate total test duration of $2.4 \mathrm{~ms}$, which is suitable for intermediate strain rate experiments. On the other hand, the bar diameter is chosen to ensure a good signal/noise ratio. The lower the diameter is, the better this ratio will be. However, higher diameters prevent the bar from deforming plastically. The $30 \mathrm{~mm}$ diameter ensures high signal/noise ratio while preventing the bar from deforming plastically. The projectile speed is measured with lasers. This crossbow rig is highly interesting because it can induce important deformation energy in the specimen. In this work, we are concerned with the intermediate strain rate range so the impact speeds of the crossbow system range from 1 to $10 \mathrm{~m} \mathrm{~s}^{-1}$. All experiments were filmed with a high speed video camera Photron APX. First, this helps in qualitative analysis of failure. Second, it allows the measurement of the impacting mass velocity. Third, it

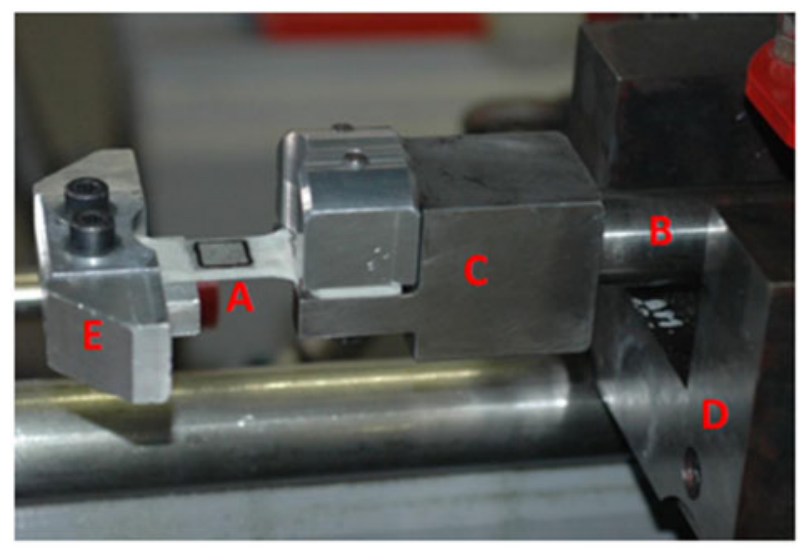

a specimen with irregular black dots for correlation; $b$ receiver bar; $c$ receiver/bar interface; $d$ impactor mass; e impactor mass receiver

5 Crossbow tensile layout 


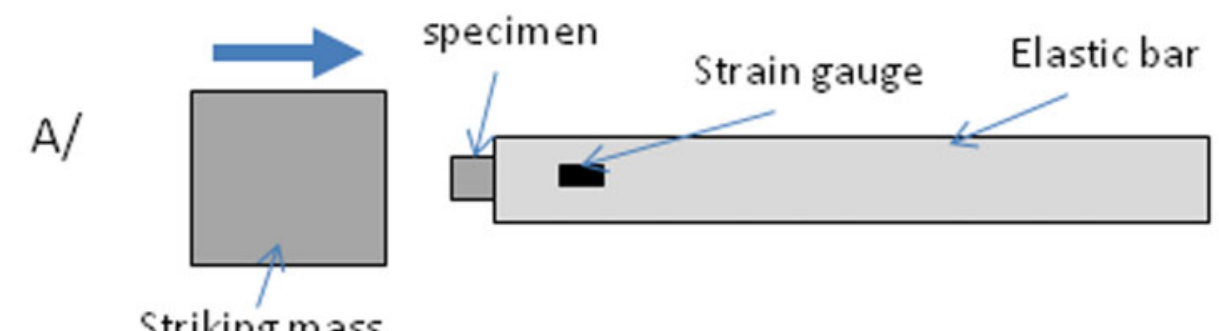

Striking mass

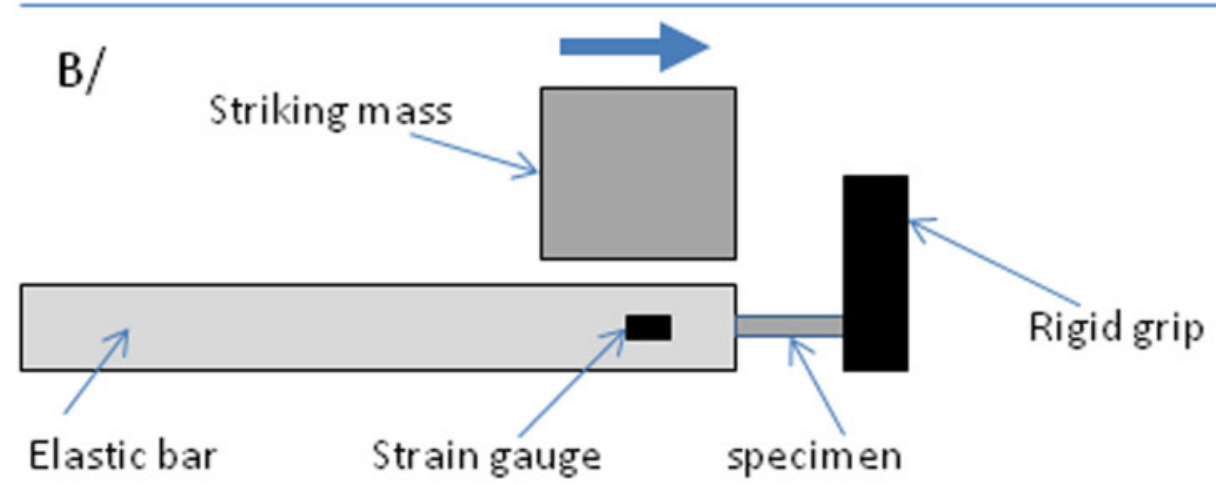

a compression set-up; $b$ tensile set-up

6 Schematic of the crossbow set-up

can be used to undertake a quantitative analysis of the specimen strain field using ICASOFT digital image correlation (DIC) software.

\section{Loading conditions}

Quasi-static tests were carried out at almost constant speed, which leads to almost constant nominal strain rate. Three strain rates were considered in the quasistatic range: $8 \mathrm{E}-3,20 \mathrm{E}-3$ and $66 \mathrm{E}-3 \mathrm{~s}^{-1}$. Two kinds of loadings were studied: monotonous and multicycle loadings. Thanks to these experiments, it is possible to identify the plastic strain and the damage $d$, which quantifies the loss in stiffness modulus.

Dynamic tensile testing was carried out at strain rates ranging from 33 to $437 \mathrm{~s}^{-1}$, which were obtained by varying the projectile velocity from 1 and $10 \mathrm{~m} \mathrm{~s}^{-1}$. It is worth noting that in dynamic experiments, the specimen can absorb an important fraction of the projectile energy. Consequently, the strain rate changes during testing. Thus, the given dynamic strain rates are average values.

Aiming at evaluating the damage at dynamic strain rates, repeated (multicycle) loading experiments were also considered. More precisely, the kinetic energy of the striker was chosen so that the specimen is damaged but not broken after the projectile impact. Subsequently, the specimen can be impacted several times until complete failure. Each time the stress-strain curve is identified. Five experiments were carried out for each type of experiment.

\section{Data processing}

Stresses and strains are given in the material coordinate system. The through thickness direction is not considered in this work. For $\left[0^{\circ}\right]$ tensile specimens, results are expressed in terms of longitudinal stresses-strain. For $\left[ \pm 45^{\circ}\right]$ tensile specimens, results are given as a shear stress/shear strain relationship.

\section{Strain measurement}

The specimens were filmed by a video camera during experiments. The camera image rate was adapted to the test duration and ranges from 1 frame/s for lower quasistatic tests to $30000 \mathrm{frames} / \mathrm{s}$ for dynamic experiments. The DIC ICASOFT software was used to identify the surface strain field. The use of full field strain measurements is of much importance to prevent any inaccuracy due slipping of the specimen or to the stiffness of the machine. The RUC is a $20 \times 20 \mathrm{~mm}^{2}$ square including a combination of stiff and soft regions, which makes local strain measurement very heterogeneous. Average longitudinal and transverse strains were evaluated from local strain field of a RUC. The strain tensor is calculated in the Green-Langrangian form. Finally, for $\left[ \pm 45^{\circ}\right]$ specimen, a rotation matrix is applied to the strain tensor to compute the shear strain in material coordinates.

The strain rate is obtained by numerical differentiation of the specimen strain signal in terms of the time. An average value is then attributed to each experiment to evaluate the strain rate sensitivity of some mechanical parameters.

\section{Stress measurement}

The INSTRON machine is equipped with a $100 \mathrm{kN}$ load cell ref 2525-171, which measures the force applied to tested specimens in the quasi-static strain rate range. For dynamic experiments, the force applied to the specimen is calculated from the strain by a strain gauge station cemented on the long elastic bar of the crossbow system.

In this work, we are interested in true stresses. Therefore, the measured force is divided by the current cross-section area of the specimen, which is measured by DIC technique. ${ }^{23,30}$ The thickness for cross-section calculations is taken constant for $\left[ \pm 45^{\circ}\right]$ specimens.

\section{Young's modulus and damage}

In addition to strain rate sensitivity of stress-strain curves, we are interested in the reduction in the stiffness 

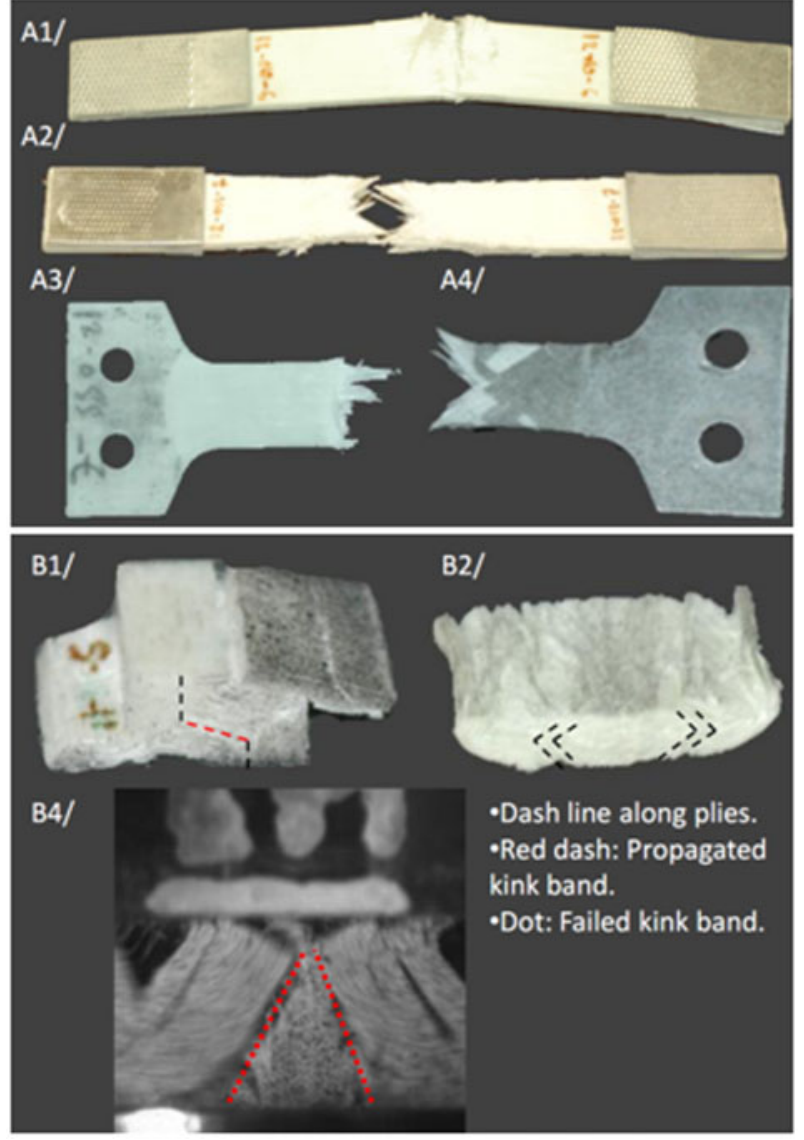

7 a failed tensile specimen [(a1) $0^{\circ}$, (a2) $\pm 45^{\circ}$, (a3) $0^{\circ}$ dynamic, and (A4) $\pm 45^{\circ}$ dynamic] and $b$ failed compression specimen [(B1) $0^{\circ}$, (B2) $\pm 45^{\circ}$ and (B3) $0^{\circ}$ dynamic]

modulus. For $0^{\circ}$ orientation specimens, Young modulus is determined by measuring initial slope between 0.5 and $1 \%$ strain. As slope is constantly changing for $\pm 45^{\circ}$ specimens, we chose to take modulus when correlation coefficient for linear regression is 0.98 . Following Bonnet, ${ }^{19}$ the damaged modulus corresponds to the slope of the line connection the zero-stress strain to the strain/stress point corresponding to the maximum of previous load.

Thanks to the multicycle experiments, it is possible to identify the plastic strain and the damage $d$, which quantifies the loss in stiffness modulus. More precisely, the damage induced after $n$ loading cycles reads

$$
d_{\mathrm{n}}=\frac{E_{1}-E_{\mathrm{n}+1}}{E_{1}}
$$

where $E_{1}$ denotes the apparent Young's modulus measured at the first cycle. It should be equal to the Young's modulus obtained by a monotonous test.

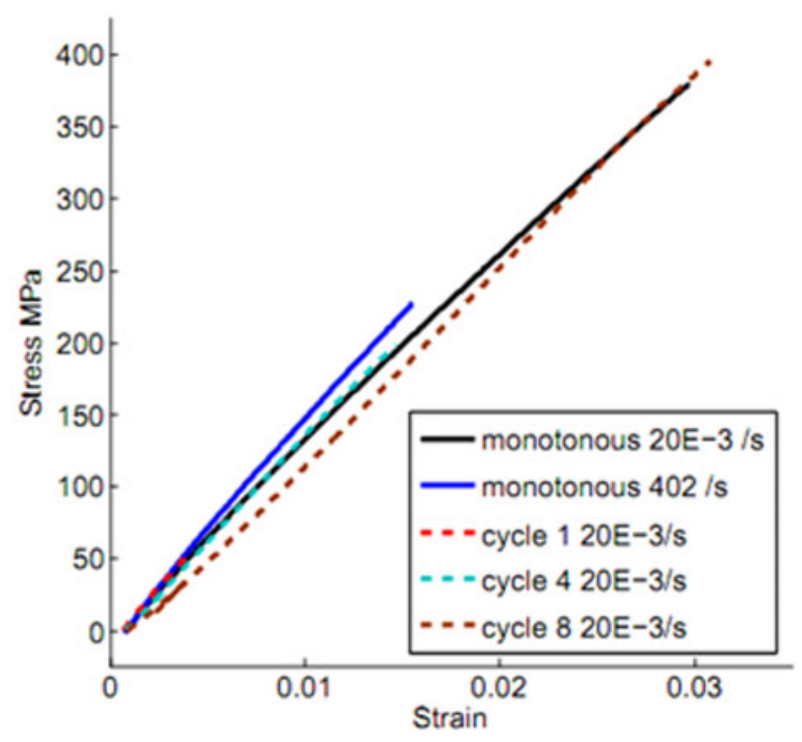

8 Tensile $0^{\circ}$ stress strain curve: monotonous and multicycle load

Moreover, $E_{\mathrm{n}}$ stands for the damage modulus measured at nth loading cycle.

\section{Results}

\section{Monotonous testing}

In this section, the effect of strain rate on the strength (maximum stress), strain at failure (maximum strain for tensile loading and strain at maximum stress for compression loading) and stress at a given value of strain are investigated under tension, compression and shear loadings.

\section{$0^{\circ}$ tension}

In this configuration, the behaviour is almost linear with brittle rupture by fibre failure [Figs. 7(A1) and 8]. Static experiments yield an initial Young's modulus of $16 \mathrm{GPa} \pm 12 \%$, a strength of $380 \mathrm{MPa} \pm 11 \%$ and $3 \cdot 0 \%$ strain at failure (Table 1). A small softening is observed before failure. Compared to the literature (Young's modulus of $\sim 14 \mathrm{GPa}$ ), this Young's modulus obtained here is slightly higher. Actually, we are using DIC method to obtain the strain in the specimen. This technique allows for local measurements. Thus, the effects of the machine stiffness and specimen slipping are canceled. This leads to lower strain and higher modulus values.

For dynamic tensile experiments at $0^{\circ}$, failure occurs $\sim 1.5 \%$ of strain and $360 \mathrm{MPa}$ of stress (Table 1). However, we have to notice that DIC measurements give lower strain values than predicted from grips displacements. This difference can be attributed to specimen slipping and/

Table 1 Strain rate sensitivity of composite behaviour in $\pm 0 / 90^{2}$ and $\pm 45^{2}$ tensile

\begin{tabular}{|c|c|c|c|c|c|c|}
\hline Strain rate & $0.0008 / \mathrm{s}$ & $0.02 / \mathrm{s}$ & $0.066 / \mathrm{s}$ & $33 / \mathrm{s}$ & $167 / \mathrm{s}$ & $402-434 / s$ \\
\hline Tensile stiffness/GPa & & $16 \pm 12 \%$ & & & & $17 \cdot 7$ \\
\hline Tensile strength/MPa & & $380 \pm 11 \%$ & & & & 360 \\
\hline Tensile strain at failure/\% & & $1 \cdot 32 \pm 5 \%$ & & & & 1.5 \\
\hline Shear stiffness/GPa & $1 \cdot 25 \pm 5 \%$ & $1 \cdot 32 \pm 5 \%$ & $1 \cdot 46 \pm 7 \%$ & $1.51 \pm 12 \%$ & $1.55 \pm 8 \%$ & $1.56 \pm 9 \%$ \\
\hline Shear strength/MPa & $95 \pm 5 \%$ & $102 \pm 9 \%$ & $113 \pm 5 \%$ & $345 \pm 18 \%$ & $220 \pm 13 \%$ & $174 \pm 12 \%$ \\
\hline Shear strain at failure/\% & $35 \pm 21 \%$ & $26 \pm 15 \%$ & $27 \pm 14 \%$ & $26 \pm 24 \%$ & $34 \pm 22 \%$ & $17 \pm 14 \%$ \\
\hline
\end{tabular}




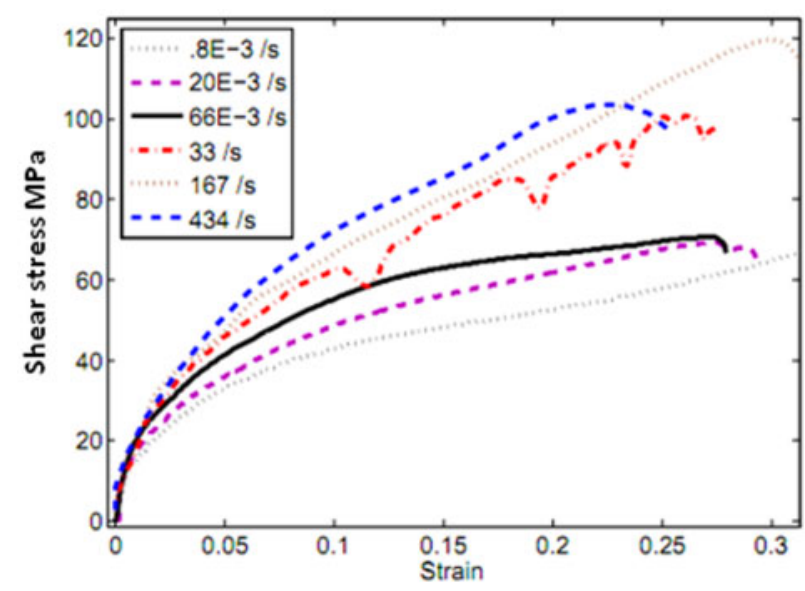

9 Tensile $45^{\circ}$ specimen stress-strain curve, monotonous

or machine stiffness. Thus, results presented along this paper are due to DIC method only. In terms of apparent Young modulus, an $11 \%$ increase is observed for dynamic experiments (402/s) when compared to quasi-static values, whereas the strength and strain at failure decrease with increasing strain rate.

\section{$45^{\circ}$ tension}

Apparent Young's modulus, strength and strain at failure are reported in Table 1 in terms of strain rate. Figure 9 depicts shear strain/shear stress evolution at different strain rates. Curves are showing an important softening and the material is able to sustain very large strains. Breaking occurs by fibres pack debonding, as can be observed in Fig. 7(A2), $\sim 26 \%$ of strain. Shear modulus and strength increase with increasing strain rate (Fig. 10a). The same tendency is observed for the stress at a specific level of strain (Fig. 10b). The shear modulus increases by $\sim 25 \%$ (from $\sim 1.25 \mathrm{GPa}$ at $0.0008 \mathrm{~s}^{-1}$ to $\sim 1.56 \mathrm{GPa}$ at $434 \mathrm{~s}^{-1}$ ), whereas the shear strength is increased by $>100 \%$. Actually, Bonnet ${ }^{19}$ and Brown et $a .^{21}$ have observed opposite tendencies; namely the shear modulus and strength were reported decreasing with increasing strain rate. The difference may be explained by the differences in the experimental testing procedure. First, Brown et al. ${ }^{21}$ and Bonnet ${ }^{19}$ have both used piezoelectric transducers to measure the force applied on the specimen. On the opposite, a crossbow rig was used in our work. The authors think that using Hopkinson bar-like method is more appropriate in dynamic testing mainly for strain rates higher than $50 \mathrm{~s}^{-1}$. Second, the specimen geometry and dimensions are different from that used by Brown et al. ${ }^{21}$ or Bonnet, ${ }^{19}$ as there is no standard dealing with the specimen design for composite dynamic experiments.

\section{Tension at intermediate angles}

Naturally, intermediate angle specimens are showing an intermediate behaviour between $0^{\circ}$ and $\pm 45^{\circ}$ specimens (Fig. 11a). We can observe a significant decrease in stiffness and a much more ductile behaviour for increasing angles up to $45^{\circ}$.

We take advantage of the DIC technique to compare local material behaviour between specimens of which the angle is 10,20 and $45^{\circ}$ (Fig. $11 b$ ). The strain in the central part of specimens has been expressed in local material coordinates. Stress is considered purely tensile in global coordinates and is brought to local material coordinates too. $+20^{\circ} /-70^{\circ}$ and $\pm 45^{\circ}$ specimens show very similar behaviour, mainly when strain is $<10 \%$. The $10^{\circ}$ specimens have similar behaviour as the previous two angles, in material coordinates, until a strain level of $2 \%$.

\section{Compression 0}

The compression behaviour of Twintex is reported in Fig. 12. The stress-strain curves obtained by $0^{\circ}$ specimen are depicted in Fig. 12a. Compression specimens present a softer quasi-elastic behaviour. The apparent modulus is $\sim 15 \mathrm{GPa}$ (Table 2). Compression specimens fail at a lower stress than tensile specimens. The failure mechanism is also different and corresponds to a kink banding mechanism as described by Jelf and Fleck ${ }^{31}$ and Rosen $^{32}$. Static specimens failure is caused by kink band broadening [Fig. 7(B1)], whereas dynamic ones is due to kink band rupture [Fig. (7B4)]. The strength (maximum
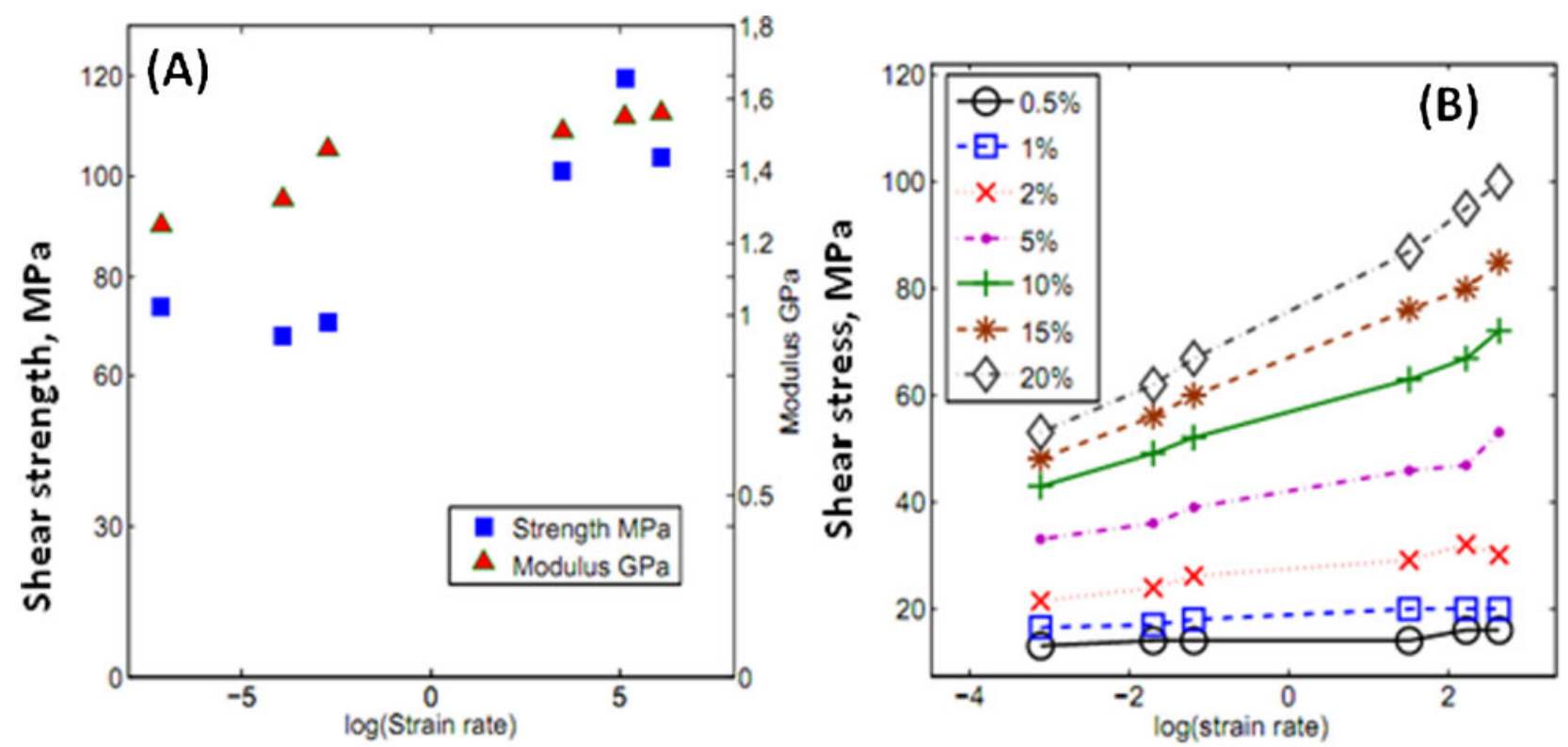

$1045^{\circ}$ specimen: $a$ sensitivity of Young's modulus and strength to strain rate and $b$ sensitivity of stress at different strain levels to strain rate 

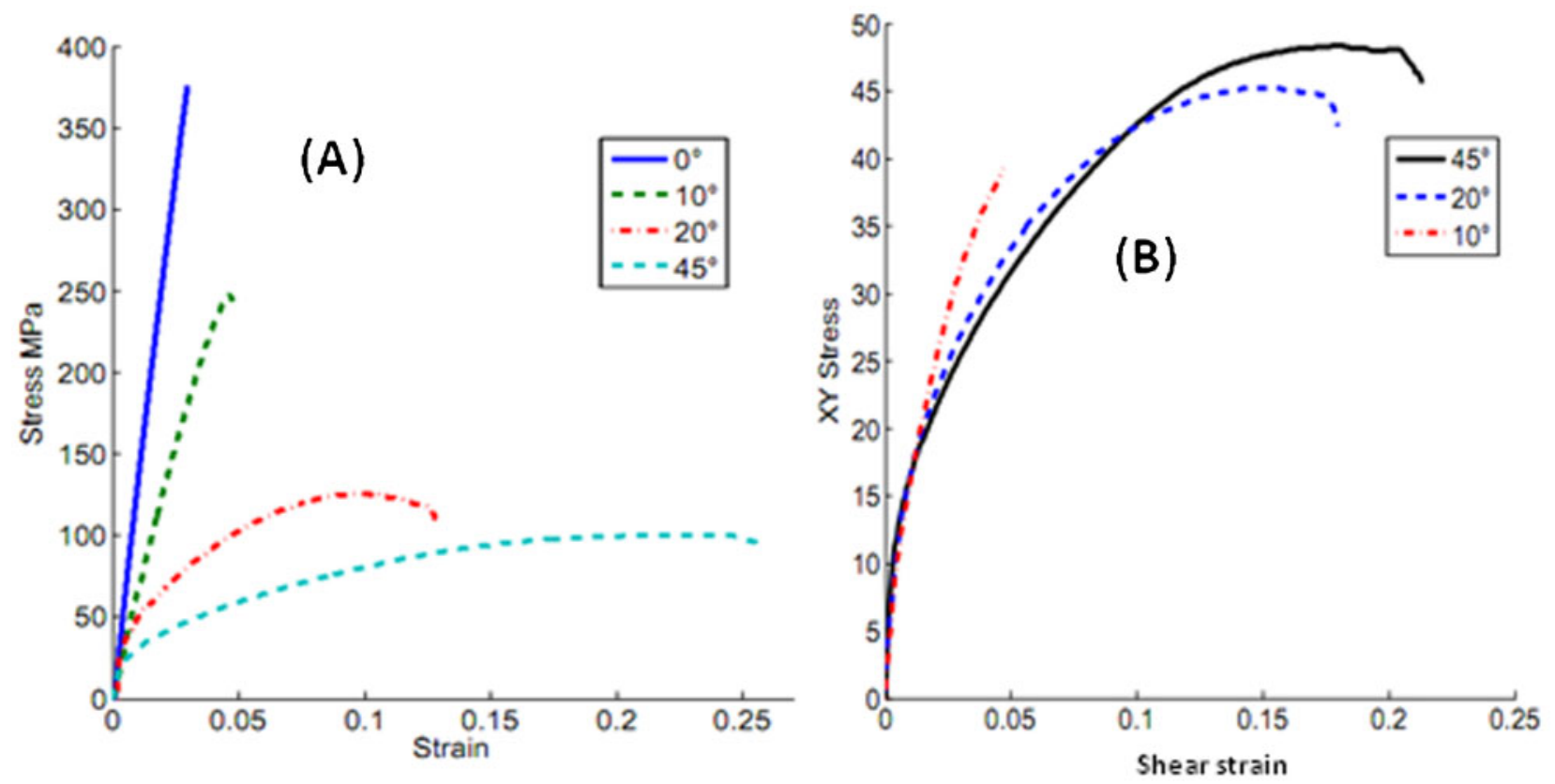

11 Tensile stress-strain curves for several angles considering a specimen coordinates and $b$ material coordinates

stress) is much higher for dynamic than for static strain rates. After failure, dynamic and static specimens present a residual crushing stress ranging from 28 to $52 \mathrm{MPa}$.

Compression $\pm 45^{\circ}$

The $45^{\circ}$ static compression specimens show a lower stiffness than tensile ones (Fig. 12b) with an apparent modulus of $1.33 \mathrm{GPa} \pm 13 \%$ (Table 2). This measurement is greatly affected by the fact that the first instants of solicitation are governed by the conformation of the specimen to anvils. Between 1 and $3 \%$ of strain, compression stress/strain relationship is similar to tensile behaviour. Around 4\%, there are structural effects occurring like barrelling and delaminating, meaning stress and strain are no more representative of the behaviour of a RUC. At this point, compression curves fall below tensile ones. Maximum stress is $58 \mathrm{MPa}$ $\pm 12 \%$ at $11 \%$ strain $\pm 8 \%$.

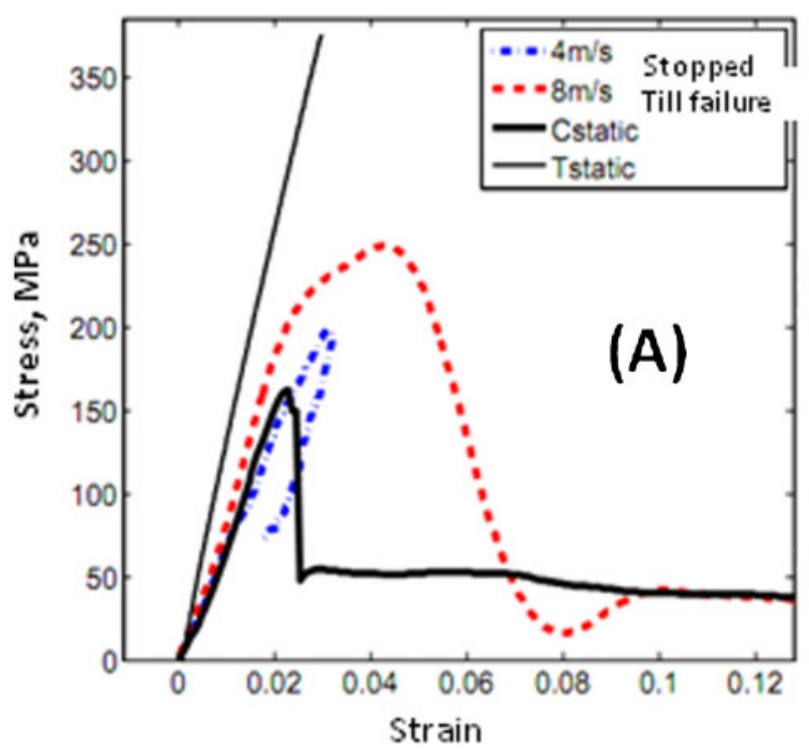

\section{Cycles and softening phenomenon}

In order to identify the part of damage and the part of plasticity in Twintex's behaviour, multicycle experiments were undertaken. These tests were carried out in tension and compression. As tension is less subject to structural effect, the presented data on damage and plastic strain come exclusively from tension testing.

\section{$0^{\circ}$ specimens}

Multicycle tensile experiments are superposed to monotonous tension in Fig. 8. Tensile behaviour presents a very small plasticity and some stiffness loss. Indeed, the specimen presents $0.1 \%$ plastic strain and $13 \%$ loss of stiffness in the last cycle before failure. Figure 13 shows damage evolution with fourth root of elastic energy. We used this variable because it is commonly applied in composite damage models. ${ }^{33}$ It is worth noting that

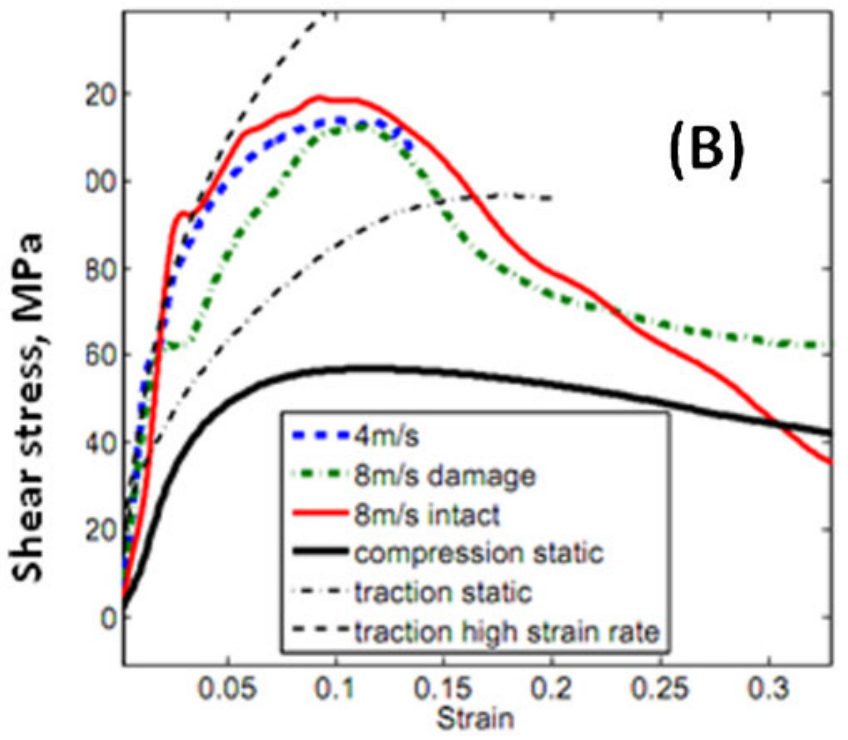

a $0^{\circ} ; b 45^{\circ}$

12 Stress-strain curves obtained for monotonous compression 


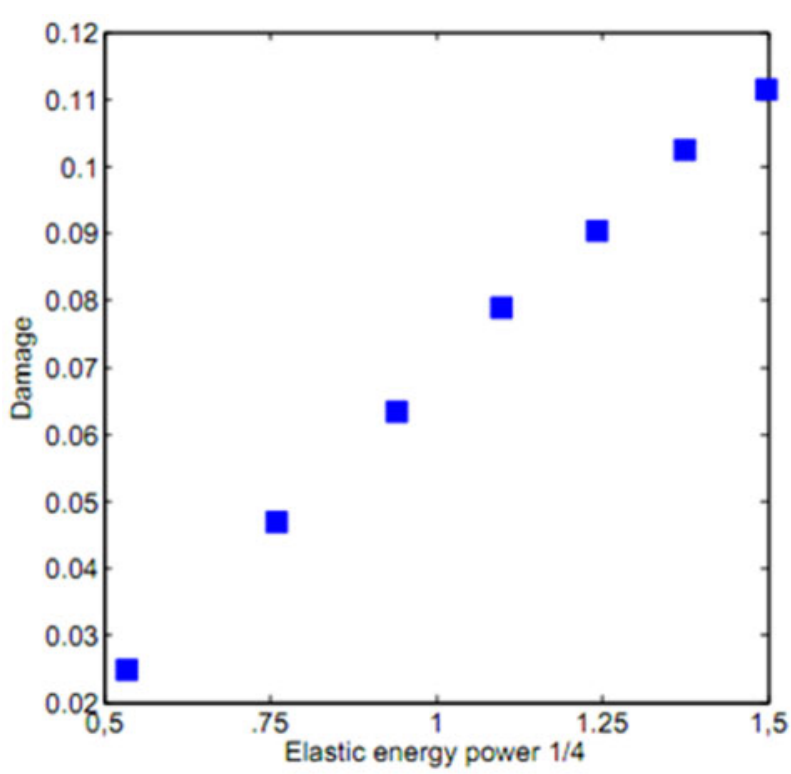

$130^{\circ}$ specimen; longitudinal damage

multicycle compression tests lead to similar results. The damage obtained, in this section, for $0^{\circ}$ specimens can be affected with some errors, given the small strain levels, while calculating the apparent modulus.

\section{$45^{\circ}$ specimens}

Figure 13 depicts stress-strain curves of multicycle experiments for $\pm 45^{\circ}$ specimens. It shows a permanent plastic strain after unloading, a significant loss in modulus and an important hysteresis behaviour (Fig. 14 and Table 3). Plastic strain is increasing with total strain (Fig. 15). At increasing strains, the plastic strain curve approaches the $(y=x)$ line. The damage is also increasing with total strain (Fig. 15). However, it approaches an asymptotic horizontal behaviour $\sim 0 \cdot 85$.

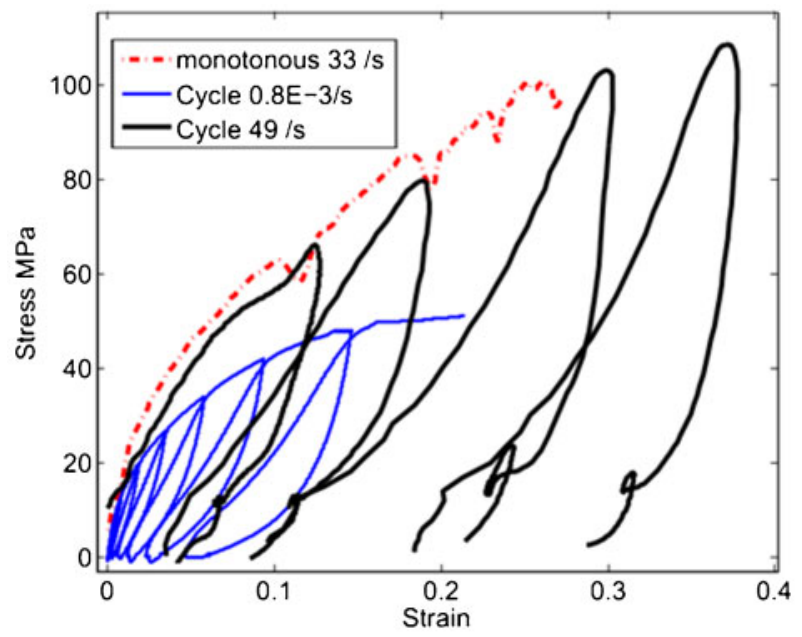

$1445^{\circ}$ specimen: multicycle testing

From dynamic and static experiments, the damage and plastic strain evolutions are slightly sensitive to strain rate (Fig. 15).

\section{Discussion}

The Twintex, a woven reinforced polypropylene, is subject to many non-linear different effects. The polypropylene matrix is sensitive to strain rate. Actually, the strain rate highly affects the polymer plastic behaviour. Namely, higher yield and flow stresses are reached for increasing strain rates. Moreover, the woven microstructure yields a non-perfect unidirectional and lateral motion, which induces softness into the RUC behaviour. In addition, the fibre undulation in the polymer matrix can greatly impact compression behaviour, as fibre orientation defaults are responsible for the initiation of kink band mechanism as proposed in Refs. 31 and 32. The 'composite' effect, by mixing two

Table 2 Strain rate sensitivity of composite behaviour in $\pm 0 / 90^{2}$ and $\pm 45^{2}$ compression

\begin{tabular}{|c|c|c|}
\hline Strain rate & $0.02 / \mathrm{s}$ & $402 / \mathrm{s}-405 / \mathrm{s}$ \\
\hline Compression stiffness/GPa & $15 \pm 18 \%$ & $15 \cdot 8$ \\
\hline Maximum stress in compression/MPa & $160 \pm 15 \%$ & 249 \\
\hline Compression strain at maximum stress $/ \%$ & $2 \cdot 1^{-}$ & $4 \cdot 4$ \\
\hline Compression shear stiffness/GPa & $1 \cdot 33 \pm 13 \%$ & $1 \cdot 51$ \\
\hline Maximum stress in compression/MPa & $58 \pm 12 \%$ & 118 \\
\hline Compression strain at maximum stress/\% & $11 \pm 8 \%$ & 9 \\
\hline
\end{tabular}

Table 3 Multicycle experiments

\begin{tabular}{|c|c|c|c|c|c|c|}
\hline Cycle & Shear modulus/MPa & Max strain/\% & Max stress/MPa & Plastic strain/\% & Damage/\% & Elastic energy $/ 10^{6} \mathrm{~J} \mathrm{~m}^{-3}$ \\
\hline$S^{*}$ initial & 1250 & 0 & 0 & 0 & 0 & 0 \\
\hline S cycle 1 & 1120 & 0.3 & $6 \cdot 6$ & 0 & 10 & 0.010 \\
\hline S cycle 2 & 868 & 0.8 & 13 & 0.06 & 30 & 0.049 \\
\hline S cycle 3 & 612 & $1 \cdot 8$ & 20 & 0.22 & 51 & $0 \cdot 16$ \\
\hline S cycle 4 & 463 & $3 \cdot 4$ & 27 & 0.56 & 63 & 0.38 \\
\hline S cycle 5 & 367 & $5 \cdot 8$ & 34 & $1 \cdot 16$ & 71 & 0.78 \\
\hline S cycle 6 & 297 & $9 \cdot 3$ & 42 & $2 \cdot 3$ & 76 & $1 \cdot 46$ \\
\hline S cycle 7 & 246 & $14 \cdot 6$ & 49 & $4 \cdot 6$ & 80 & $2 \cdot 43$ \\
\hline$D+$ initial & 1510 & 0 & 0 & 0 & 0 & 0 \\
\hline $\mathrm{D}$ cycle 1 & 262 & $12 \cdot 6$ & 66 & 3.5 & 83 & $3 \cdot 0$ \\
\hline D cycle 2 & 243 & $18 \cdot 8$ & 80 & $8 \cdot 6$ & 84 & $4 \cdot 0$ \\
\hline D cycle 3 & 284 & $29 \cdot 8$ & 103 & $18 \cdot 0$ & 82 & $6 \cdot 1$ \\
\hline D cycle 4 & 275 & 37 & 108 & $28 \cdot 3$ & 82 & $4 \cdot 7$ \\
\hline
\end{tabular}

*S static $\left(0.02 \mathrm{~s}^{-1}\right)$

$\dagger D$ dynamic $50 \mathrm{~s}^{-1}$. 


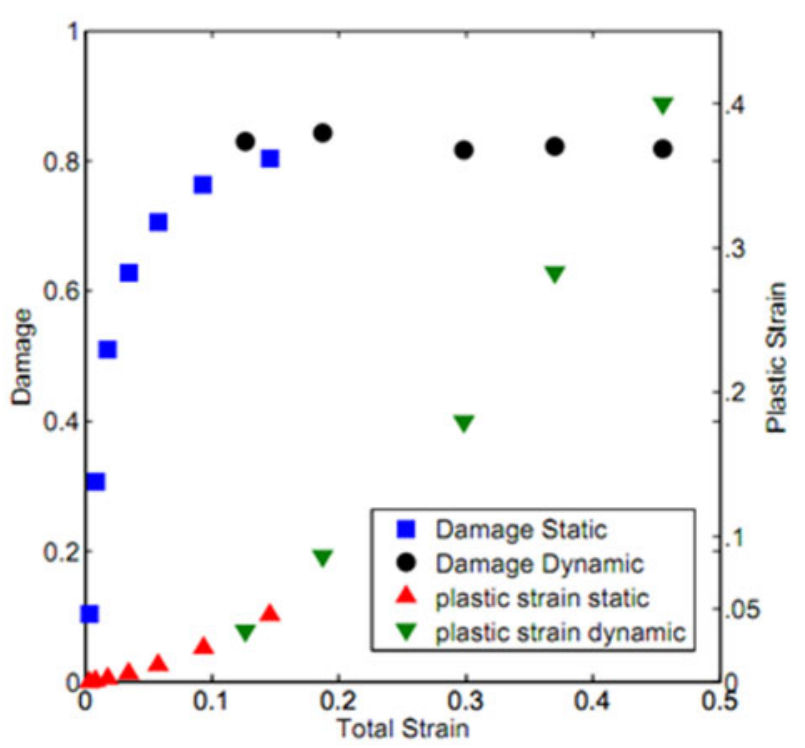

15 Damage, plastic strain and function of total strain; quasi- static and dynamic strain rate

components, also means that many forms of cracking and debonding can occur between matrix, fibres and ply. This yields damages and delamination as analysed by Bonnet. $^{19}$

Tensile testing of Twintex at $0^{\circ}$ confirmed some loss of stiffness compared to pure glass but the behaviour was mainly linear because of the good fibre content and the microstructural effect tending to straightening fibres. The failure is brittle because it is due to fibre failure. Tensile behaviour at $45^{\circ}$ highly depends on the non-linear properties of the polymer matrix. Higher rates induce higher stress as shown by our dynamic experiments.

Compression testing showed a natural loss in stiffness for $0^{\circ}$ specimens considering fabric undulations. Increasing strain rate induces again an increase in stiffness but an even greater increase in strength and strain at failure. As demonstrated using kinking theory, ${ }^{33}$ the matrix properties highly influence the compressive behaviour of a long fibre composite. The matrix is less plastic and presenting a much higher ultimate stress at high strain rate. Hence, the initiation of kinking is reduced, which give better compressive properties for the GF/PP woven composite at high speeds. This explains the higher stress for high strain rate $0^{\circ}$ compression experiments. The kinking development can be delayed by inertia effects, which yields higher strength.

Results, obtained with $45^{\circ}$ compression specimens, are consistent with tensile experiments at the same angle, except that failure initiate at a smaller strain by delamination rather than fibre debonding.

\section{Conclusions}

An experimental programme was undertaken on a promising composite material. The combination of the crossbow system with DIC technique and a precise displacement averaging over the RUC gave us an improvement in both force and strain measurement accuracy. These improvements are very important in the measurement of Twintex tensile, compression and shear behaviour at quasi-static and intermediate strain rates. Multicycle testing was also carried out at small and large strain rates thanks to a precise calibration of the crossbow energy. Results confirmed the important effects of strain rate on Twintex behaviour. Interestingly, a slower solicitation results in a softer response even at very small strain rates. This could be expected because of the polymeric nature of the matrix. Different types of failure behaviour have been identified depending on material/ loading orientation. Furthermore, $0^{\circ}$ compression specimen showed an important strength sensitivity to strain rate, confirming the determining role of the matrix in compression failure as investigated by many authors with the kinking theory.

\section{References}

1. B. Griffith: 'Glass-reinforced thermoplastic succeeds in car crash structure', Compos. Technol., 2006, 5, 52-54.

2. M. Lidgett, R. Brooks, N. Warrior and K. A. Brown: 'Virtual modelling of microscopic damage in polymer composite materials at high rates of strain', Plast. Rubber Compos., 2011, 40, 324-332.

3. M. R. Allazadeh and S. N. Wosu: 'High strain rate compressive tests on woven graphite epoxy composites', Appl. Compos. Mater., $2011, \mathbf{1 8}, 311-325$

4. F. Turan, M. R. Allazadeh and S. N. Wosu: 'Effects of the loading direction on high strain rate behavior of woven graphite/epoxy composites', J. Mater. Sci. Res., 2012, 1, 69-86.

5. M. M. Shokrieh, R. Mosalmani and M. J. Omidi: 'Strain-rate dependent micromechanical method to investigate the strength properties of glass/epoxy composites', Compos. Struct., 2014, 111, 232-239.

6. R. Foroutan, J. Nemes, H. Ghiasi and P. Hubert: 'Experimental investigation of high strain-rate behaviour of fabric composites', Compos. Struct., 2013, 106, 264-269.

7. H. L. Gowtham, J. R. Pothnis, G. Ravikumar and N. K. Naik: 'High strain rate in-plane shear behavior of composites', Polym. Test, 2013, 32, 1334-1341.

8. J. Fitoussi, F. Meraghni, Z. Jendli, G. Hug and D. Baptiste: 'Experimental methodology for high strain-rates tensile behaviour analysis of polymer matrix composites', Compos. Sci. Technol., 2005, 65, 2174-2188

9. J. López-Puente and S. Li: 'Analysis of strain rate sensitivity of carbon/epoxy woven composites', Int. J. Impact Eng., 2012, 48, 54 64.

10. Ö. Akil, U. Yıldırım, M. Güden and I. W. Hall: Effect of strain rate on the compression behaviour of a woven fabric S2-glass fiber reinforced vinyl ester composite. Polym. Test, 2003, 22, 883-887.

11. M. Guden, U. Yildirim and I. W. Hall: Effect of strain rate on the compression behavior of a woven glass fiber/SC-15 composite. Polym. Test, 2004, 23, 719-725.

12. M. V. Hosur, M. Adya, S. Jeelani, U. K. Vaidya and P. K. Dutta: Experimental Studies on the High Strain Rate Compression Response of Woven Graphite/Epoxy Composites at Room and Elevated Temperatures. J Reinforced Plast Compos, 2004, 23, 491514

13. M. V. Hosur, J. Alexander, U. K. Vaidya, S. Jeelani and A. Mayer: Studies on the off-axis high strain rate compression loading of satin weave carbon/epoxy composites. Compos. Struct., 2004, 63, 75-85.

14. J. Rodriguez, I. S. Chocron, M. A. Martinez and V. SanchezGalvez: High strain rate properties of aramid and polyethylene woven fabric composites. Compos B, 1996, 27, 147-154.

15. I. S. Chocron Benloulo, J. Rodriguez, M. A. Martinez and V. Sanchez-Galvez. Dynamic tensile testing of aramid and polyethylene fiber composites. Int. J. Impact Eng., 1997, 19, 135-146.

16. M. Todo, K. Takahashi, P. Beguelin and H. H. Kausch: 'Strainrate dependence of the tensile fracture behaviour of woven-cloth reinforced polyamide composites', Compos. Sci. Technol., 2000, 60, $763-771$.

17. W. Hufenbach, Hornig, B. Zhou, A. Langkamp and M. Gude: 'Determination of strain rate dependent through-thickness tensile properties of textile reinforced thermoplastic composites using Lshaped beam specimens', Compos. Sci. Technol., 2011, 71, 1110-1116.

18. R. A. Govender, G. S. Langdon, G. N. Nurick and T. J. Cloete: 'Impact delamination testing of fibre reinforced polymers using Hopkinson pressure bars', Eng. Fract. Mech., 2013, 101, 80-90.

19. B. Bonnet: 'Comportement au choc de matériaux composites pour applications automobiles', PhD thesis, Ecole Nationale Supérieure des Mines de Paris, Paris, France, 2005. 
20. G. Reyes and U. Sharma: 'Analysis of woven glass fiber reinforced thermoplastic composites under varying strain rates', http:// speautomotive.com/SPEA_CD/SPEA2009/pdf/VPT/VPT-15.pdf

21. K. Brown, R. Brooks and N. Warrior: 'The static and high strain rate behaviour of a commingled E-glass/polypropylene woven fabric composite', Compos. Sci. Technol., 2010, 70, 272-283.

22. C. Priem, R. Othman, P. Rozycki and D. Guillon: 'Experimental investigation of the crash energy absorption of 3D-braided thermoplastic composite tubes', Compos. Struct.,, 2014, 116, 814 826.

23. R. Othman, S. Aloui and A. Poitou: 'Identification of nonhomogeneous stress fields in dynamic experiments with a nonparametric method', Polym. Test., 2010, 29, 616-623.

24. S. Aloui, R. Othman, E. Verron and P. Guegan: 'Semi-analytic inverse method for rubber testing at high strain rates', Mech. Res. Commun., 2013, 47, 97-101.

25. R. Othman, P. Guegan, G. Challita, D. Lebreton and F. Pasco: 'A modified servo-hydraulic machine for testing at intermediate strain rates', Int. J. Impact Eng., 2009, 36, 460-467.

26. S. Hamdan and G. M. Swallowe: 'A crossbow system for highstrain-rate mechanical testing', Meas. Sci. Technol., 1996, 7, 10681072 .
27. Z. Jendli, F. Meraghni, J. Fitoussi and D. Baptiste: 'Micromechanical analysis of strain rate effect on damage evolution in sheet molding compound composites', Composites A, 2004, 35A, 779-785.

28. L. L. Wang and Z. J. Sun: 'Studies on rate dependent damage evolution in polymer blends in high strain rates', Plast. Rubber Compos., 2008, 37, 246-250.

29. ISO 527-4:1997: 'Plastics. Determination of tensile properties. Part 4: test conditions for isotropic and orthotropic fibre-reinforced plastic composites', iso 527-4, 1997.

30. S. Aloui, R. Othman, P. Guegan, A. Poitou and S. Elborgi: 'Nonparametric identification of the non-homogeneous stress in high strain-rate uni-axial experiments', Mech. Res. Commun., 2008, 35, 392-397.

31. P. M. Jelf and N. A. Fleck: 'Compression failure mechanisms in unidirectional composites', J. Compos. Mater., 1992, 26, 2706.

32. B. W. Rosen: 'Mechanics of composite strengthening', Fiber Compos., 1964, 37-75.

33. L. Iannucci and M. L. Willows: 'An energy based damage mechanics approach to modelling impact onto woven composite materials - Part I: numerical models', Composites A, 2006, 37A, 2041-2056. 